\title{
Autoradiographic Localization of Human Calcitonin Sensitive Binding Sites in Rat Brain
}

\author{
Hiromichi Nakamuta, Yoshihiko Itokazu, Masao Koida, \\ Ronald C. Orlowski ${ }^{1}$ and Richard M. Epand ${ }^{2}$ \\ Department of Pharmacology. Faculty of Pharmaceutical Science, Setsunan University. \\ 45-1 Nagaotoge-cho, Hirakata, Osaka 573-01. Japan \\ 'Private Consultamt, Belmont, CA 94002, U.S.A. \\ 'Department of Biochemistry, Health Sciences Centre, McMaster Universily, \\ Hamilton, Ontario ISN 375, Canada \\ Received February 22. 1991 Accepted June 10, 1991
}

\begin{abstract}
Using ${ }^{125} \mathrm{I}$-salmon calcitonin (sCT) as a ligand, in vitro autoradiography of rat brain outlined specific anatomical localization of human calcitonin (hCT) sensitive binding sites. The results presented herein show that there are hCT sensitive binding sites in the ventral part of the lateral septum among the $\mathrm{sCT}$ specific binding sites distributed throughout the diencephalon.
\end{abstract}

When administered centrally, calcitonin (CT) is known to exert a variety of effects, such as anorexia (1). analgesia (2) and inhibition of gastric acid secretion (3), suggesting that CT may have a role as a neuromodulator, in addition to it's classical peripheral hormone actions (4). However, most of the past studies have used salmon CT ( $\mathrm{SCT}$ ) instead of mammalian CTs, possibly because sCT has a potent biological activity, it is metabolically stable in mammals, and unlike mammalian CTs, it has high affinity binding sites (5). The studies about conformational structures of CT have suggested that the central region of $\mathrm{sCT}$ can fold into an amphipathic $\alpha$-helix in the environment of amphiphiles, and this conformational feature plays an important rolc in the interaction with the biomembrane and possibly with the receptor $(6,7)$. On the other hand, it is also known that certain $\mathrm{SCT}$ analogs, such as $\left[\mathrm{Gly}^{8}, \mathrm{Ala}^{16}\right]$-des-Leu ${ }^{19}$-sCT (sCTAl), which does not form an $\alpha$-helix or interact with amphiphiles, nevertheless retains most of the biological activity of the unmodified SCT (8).
Recently it was reported that $\mathrm{sCT}$ receptors in a rat brain membrane fraction can be classified into at least two kinds of subtypes, the CT-L type (L: linear) that interacted with sCTAl with a high affinity and the CT-H type ( $\mathrm{H}$ : helical) that interacted with sCTA1 with a low affinity (9). The CT-L type receptor, but not the CT-H type receptor, bound with high affinity $\left(\mathrm{IC}_{50}=2 \times 10^{-9} \mathrm{M}\right)$ to human $\mathrm{CT}$ (hCT) (9).

Wc thus examined whether the heterogeneity of SCT receptors, characterized in terms of CT-ligands specificity, would exhibit area-specific heterogeneity by in vitro autoradiography of rat brain.

SCT was supplied by the Armour Pharmaceutical Co. (Kankakee, IL, U.S.A.), and hCT was purchased from the Peptide Institute, Inc. (Minoh, Osaka, Japan). SCT was labeled with ${ }^{25}$ I (Amersham: Buckinghamshire, U.K.) according to the Iodo-gen (Pierce: Rockford, IL, U.S.A.) method (10) and free ${ }^{125}$ I removed with a C18 Amprep minicolumn (Amersham). The specific radioactivity of the 
labeled peptide was approximately 1000 $\mathrm{Ci} /$ mmole. Whole brains of male SpragueDawly rats (Crj: $8-10$ weeks old) were frozen in liquid propane cooled with liquid nitrogen. Coronal brain sections $(20 \mu \mathrm{m})$ were prepared at $-20^{\circ} \mathrm{C}$, referring to the rat brain atlas of Paxinos and Watson (11). Brain sections were thaw-mounted onto gelatin-coated slides and kept overnight under vacuum at $-30^{\circ} \mathrm{C}$. For the binding studies, the coronal sections including the anterior regions of the hypothalamus (atlas (11) Figs. 18 to 24) and for the autoradiographic studies, some adjacent pairs of coronal sections (atlas (11) Figs. 18 to 36) which were prepared at constant interval were used. Before the binding studies, the sections were brought to room temperature and preincubated for $30 \mathrm{~min}$ at $25^{\circ} \mathrm{C}$ in Dulbecco's PBS (PBS) and then incubated for $2 \mathrm{hr}$ at $25^{\circ} \mathrm{C}$ with $1 \times 10^{-10} \mathrm{M}^{125} \mathrm{I}-\mathrm{sCl} \mathrm{C}^{\circ}$ in PBS containing $2 \%$ BSA and $0.1 \%$ bacitracin. The nonspecific binding was determined in the presence of $1 \times 10^{-7} \mathrm{M}$ sCT. Three 5-min wash periods with ice-cold PBS followed the incuba- tion. After drying, the sections were apposed against Hyperfilm- ${ }^{3} \mathrm{H}$ (Amersham) at $-20^{\circ} \mathrm{C}$ for 4 days. These films were developed and fixed in Processing Chemicals (Sigma: St. Louis, MO, U.S.A.). The tissue sections were ther firod in nowtrolized formalin and stained with thionine.

The sCT specific binding of ${ }^{125} \mathrm{I}-\mathrm{sCT}$ to brain sections occurred in a saturable manner. The binding increased depending on the reaction time and temperature, reaching a plateau within $2 \mathrm{hr}$ at $25^{\circ} \mathrm{C}$ (not shown). The percentage of the specific binding to the total binding was about $60 \%$ in this condition. From the Scatchard analysis, this SCT specific binding had a dissociation constant of $2.2 \times 10^{-9} \mathrm{M}$ and the maximum binding of $9.1 \times 10^{-15}$ $\mathrm{mol} / \mathrm{section}$. SCT and hCT inhibited this binding in a dose-dependent manner (Fig. 1). The $\mathrm{IC}_{50}$ value of $\mathrm{SCT}$ was $1.2 \times 10^{-9} \mathrm{M}$, far lower than that $\left(>10^{-6} \mathrm{M}\right)$ of hCT. The displacement curve of hCT was shallow in comparison with the sharp one for sCI (Fig. 1). Hill coefficients of sCT was 0.96 , but that of

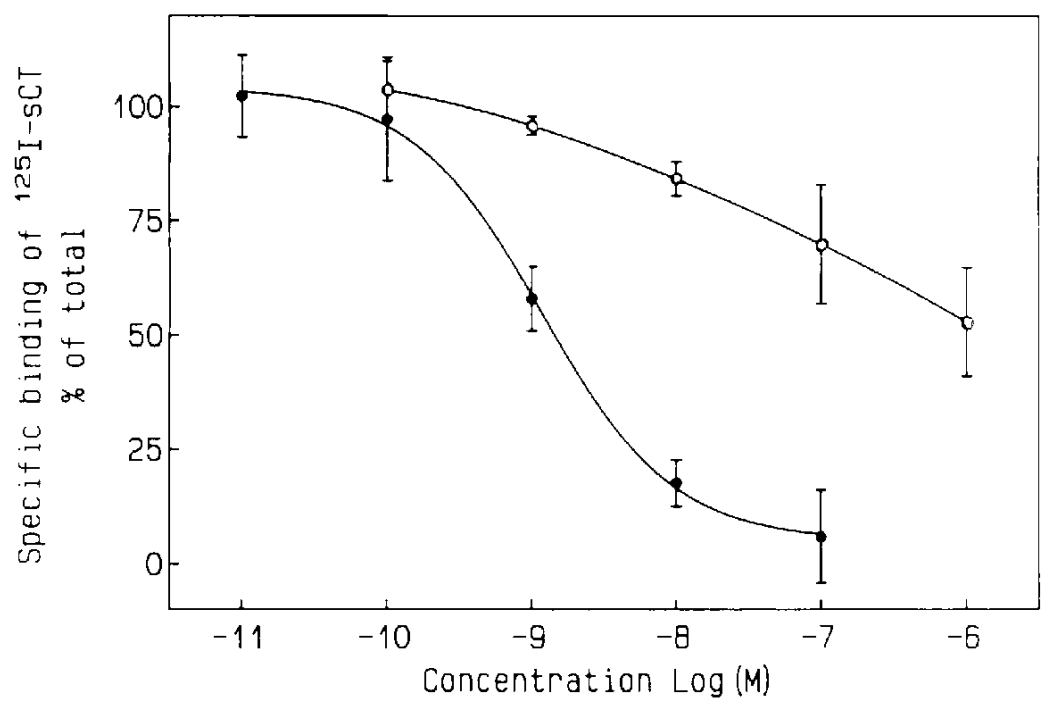

Fig. 1. Displacement of ${ }^{125} \mathrm{I}-\mathrm{SCT}$ specific binding by sCT and hCT. The coronal sections of the anterior re gion of the hypothalamus were incubated with $1 \times 10^{-10} \mathrm{M}{ }^{125} \mathrm{I}-\mathrm{sCT}$ at $25^{\circ} \mathrm{C}$ for $2 \mathrm{hr}$ in the competition with increasing concentrations of SCT (O) and hCT ( ). The specific binding was taken as the suppressible binding in the presence of $10^{-6} \mathrm{M}$ sCT. Each point represents the mean and its vertical bar. the $\mathrm{S}$. E. $(n=4)$ 
hCT was less than 0.5 , indicating that there are some differences in the nature of the receptor binding between $\mathrm{SCT}$ and hCT.
The distribution patterns of ${ }^{125} \mathrm{I}-\mathrm{sCT}$ binding sites are shown in Fig. 2 (A, B and C). There were autoradiographic grains throughout the
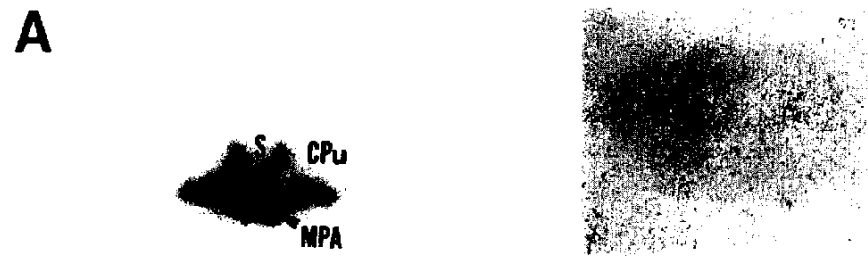

B
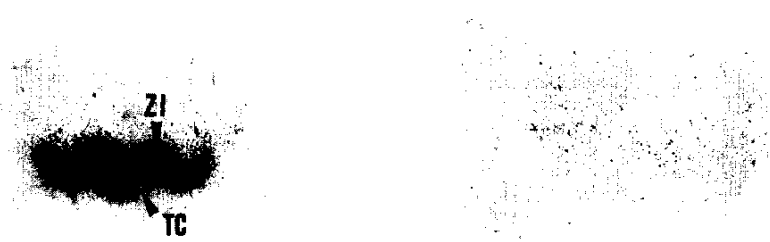

C
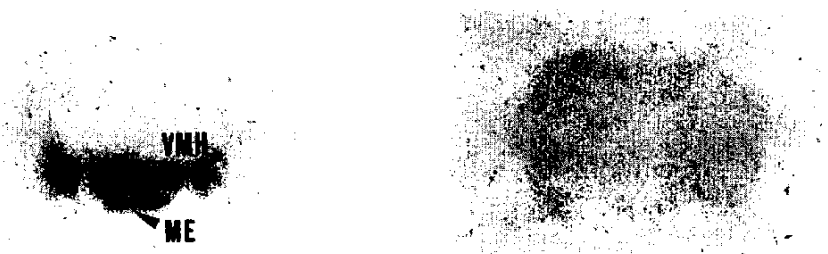

D
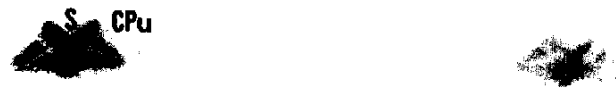

E
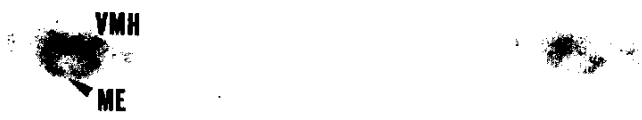

Fig. 2. Autoradiographic localization of sCT specific binding (A, B, C) and hCT sensitive binding (D, E) in some adjacent pairs of rat brain coronal sections. Left panels: ${ }^{125}$ I-sCT binding alone. Right panels: ${ }^{125} \mathrm{I}$-sCT binding in the presence of $10^{-7} \mathrm{M} \mathrm{sCT}(\mathrm{A}, \mathrm{B}, \mathrm{C})$ or $10^{-8} \mathrm{M}$ hCT $(\mathrm{D}, \mathrm{E})$. The approximate levels of sections are as follows: A, $8.74 \mathrm{~mm} ; \mathrm{B}, 7.20 \mathrm{~mm} ; \mathrm{C}, 6.20 \mathrm{~mm} ; \mathrm{D}, 8.70 \mathrm{~mm}, \mathrm{E}, 6.20 \mathrm{~mm}$, from the interaural line. S, septum; CPu, corpus putamen; MPA, medial preoptic area; ZI, zona incerta; TC, tuber cinereum; VMH, ventromedial hypothalamic nucleus; $\mathrm{ME}$, median eminence. 
diencephalon, and all grains disappeared in the presence of $1 \times 10^{-7} \mathrm{M}$ sCT (Fig. 2, A, B and $C$ ). The relatively high density of grains within these sections appeared in the ventral part of the lateral septum, the ventral part of the corpus striatum, medial preoptic area and zona incerta. In the hypothalamus, the preoptic and anterior regions had high concentrations of grains in comparison with the posterior and mammillary regions. No significant binding was detectable in the cerebral cortex (Fig. 2, A, B and C). The distribution patterns of grains corresponded well to the results reported by others (12). An addition of $1 \times$ $10{ }^{\wedge} \mathrm{M}$ hCT was found to suppress the grains in the ventral part of the lateral septum selectively (Fig. 2D). Though the data are not shown, the suppression became more complete with $1 \times 10^{-7} \mathrm{M} \mathrm{hCT}$, but the selectivity was lost.

It was reported that $\mathrm{sCl}$ bound to both receptor subtypes with similar affinities, but hCT bound only to the CT-L receptor with a high affinity in the brain membrane fractions (9). In the autoradiographic studies reported hercin, SCT specific binding in a particular brain region was selectively depressed by a relatively low concentration of hCT, suggesting that there exists hCT sensitive binding sites in certain areas of the rat brain. Two cell groups constitute the ventral part of the lateral septum: lateral septal nucleus, ventral part and septohypothalamic nucleus. Though the functions of these regions are obscure, they receive afferents from the anterior hypothalamic area and the ventromedial nucleus (13). We have also noted that there is a high correlation between hypocalcemic activity and affinity to the CT-L type receptor, rather than to the CT-H type receptor (9). In addition, an electrophysiological study has shown the presence of subpopulations of neurons with different reactivities for $\mathrm{hCT}$ in rat brain (14). Though hCT was used instead of rat CT throughout these studies, it is known that rat $\mathrm{CT}$ is very similar to hCT chemically and immunologically (15). It is likely that rat brain is equipped with at least two different types of binding sites for CTs, and the hCT-sensitive sites found in this study may function as the receptor for some yet undefined physiological action of CT.

\section{Acknowledgments}

We wish to express our gratitude to Mr. Y. Asada, Miss M. Inada and Miss S. Ueoka for their technical assistance. This research was supported, in part, by NSERC, Canada.

\section{REFERENCES}

1 Freed, W.J., Perlow, M.J. and Wyatt, R.J.: Calcitonin: Inhibitory effect on cating in rats. Science 206, $850-852$ (1979)

2 Pecile, A., Ferri, S., Braga, P.C. and Olgiati, V.R.: Effcct of intracerebroventricular calcitonin in the conscious rabbit. Experientia 31, 332-333 (1975)

3 Morley, J.E., I.evine, A.S. and Silvis, S.E.: Intraventricular calcitonin inhibits gastric acid secretion. Science 214, 67I-673 (1981)

4 Macintyre, I.: Endogenous calcitonin. In The Calcitonins: Physiology and Pharmacology, Edited by Azria, M., p. 21-66, Karger, Basel (1989)

5 Nakamuta, H., Furukawa, S., Koida, M. Yajima, H., Orlowski, R.C. and Schlueter, R.: Spccific binding of ${ }^{125}$ l-salmon calcitonin to rat brain: Regional variation and calcitonin specificity. Japan. I. Pharmacol. 31, 53-60 (1981)

6 Epand, R.M., Epand, R.F., Orlowski, R.C. Schlueter, R.J., Boni, I.T. and Hui, S.W.: Amphipathic helix and its relationship to the interaction of calcitonin with phospholipids. Biochemistry 22, 5074-5084 (1983)

7 Kaiser, E.T. and Kezdy, F.J.: Amphiphilic secondary structure: Design of peptide hormones. Science $223,249-255$ (1984)

8 Epand, R.M., Epand, R.F. and Orlowski, R.C.: Biologically active calcitonin analogs which have minimal interactions with phospholipids. Biochem. Biophys. Res. Commun. 152, $203-207$ (1988)

9 Nakamuta, H., Orlowski, R.C. and Epand, R.M.: Evidence for calcitonin receptor heterogeneity: Binding studies with nonhelical analogs. Endocrinology 127, 163-169 (1990)

10) Fraker, P.J. and Spcck, J.C., Jr.: Protein and cell membrane iodinations with a sparingly soluble chloramide, 1,3,4.6-tetrachloro-3 $\alpha, 6 \alpha$-diphenylglycoluril. Biochem. Biophys. Res. Commun. 80. $849-857$ (1978)

11 Paxinos, $G$. and Watson, C.: The Rat Brain in 
Stereotaxic Coordinates 2nd Edn., Academic Press, Inc., San Diego (1986)

12 Olgiati, V.R., Guidobono, F.. Netti, C. and Pecile, A.: Localization of calcitonin binding sites in rat central nervous system: Evidence of its neuroactivity. Brain Res. 265, 209-215 (1983)

13 Bleier, R. and Byne, W.: Septum and hypothalamus. In The Rat Nervous System, Edited by Paxinos, G., Vol. 1, p. 87-118, Academic Press,
Sydney (1985)

14 Twery, M.J. and Moss, R.L.: Calcitonin and calcitonin gene-related peptide alter the excitability of neurons in rat forebrain. Peptides 6, 373-378 (1985)

15 Byfield, P.G.H., McLoughlin, J.L., Matthews, E.W. and Macintyre, I.: A proposed structure for rat calcitonin. FEBS Lett. 65, 242-245 (1976) 